\title{
4-Nitroquinoline 1-Oxide-Induced Tongue and Esophagus Carcinogenesis in Obese and Diabetic TSOD Mice
}

\author{
Takuji Tanaka a, b, e, Kunihiro Kawabatac, \\ Shigeyuki Sugie ${ }^{\mathrm{d}}$
}

\begin{abstract}
Background: Obesity and diabetes mellitus are associated with lifestyle-related carcinogenesis. They are also risk factors of esophageal adenocarcinoma, but there are only a few reports on association between obesity/diabetes and development of squamous cell carcinoma in the oral cavity and esophagus. In this study, we therefore aimed to determine whether obesity and diabetes affect oral and esophageal carcinogenesis using model mice of obesity and diabetes, the Tsumura Suzuki obese diabetes (TSOD) and Tsumura Suzuki non-obesity (TSNO) control mice, which were treated with 4-nitroquinoline 1-oxide (4-NQO) to produce tongue and esophageal carcinomas.
\end{abstract}

Methods: We used 28 each of the male TSOD and TSNO mice of 8 weeks of age. They were divided into the 4-NQO-treated group $(\mathrm{n}=20)$ and untreated group $(\mathrm{n}=8) .4-\mathrm{NQO}$ was administered to mice in drinking water at a dose level of 20 ppm for 8 weeks. The untreated group was given distilled water without 4-NQO. At 28 experimental weeks, histopathological examination was performed on all organs including tongue and esophagus. We performed analysis of histopathology of all organs which included buccal capsule (a tongue)/esophagus after an experiment start in 28 weeks. Fasting plasma glucose (FPG) and lipid parameters including total cholesterol (T-Cho), triglyceride (TG), high-density lipoprotein (HDL)cholesterol and low-density lipoprotein (LDL)-cholesterol were measured and all these parameters were compared between the two genotypes. Also, mRNA expression of eight cytokines including

Manuscript submitted August 1, 2017, accepted August 15, 2017

aDepartment of Diagnostic Pathology (DDP) \& Research Center of Diagnostic Pathology (RC-DiP), Gifu Municipal Hospital, Gifu City, Gifu 500-8513, Japan

bDepartment of Tumor Pathology, Gifu University Graduate School of Medicine, Gifu City, Gifu 501-1194, Japan

'Palliative Care Center, Tokai Central Hospital, 4-6-2 Sohara-Higashijimacho, Kakamigahara 504-8601, Japan

dDepartment of Pathology, Murakami Memorial Hospital, Asahi University, School of Dentistry, 3-23 Hashimoto-cho, Gifu City, Gifu 500-8523, Japan

${ }^{e}$ Corresponding Author: Takuji Tanaka, Department of Diagnostic Pathology (DDP) \& Research Center of Diagnostic Pathology (RC-DiP), Gifu Municipal Hospital, Gifu City, Gifu 500-8513, Japan. Email: takutt@gmhosp.gifu.gifu.jp

doi: https://doi.org/10.14740/wjon1038w interleukin (IL)-1 $\beta$, IL-6, IL-17, interferon (IFN)- $\gamma$, keratinocytederived cytokine (KC), macrophage inflammatory protein (MIP)$1 \alpha$, MIP-2, and tumor necrosis factor (TNF)- $\alpha$ in the esophageal mucosa was assayed.

Results: 4-NQO treatment produced proliferative squamous cell lesions (dysplasia, papilloma and carcinoma) in the tongue and esophagus of both the TSOD and TSNO mice. The incidence and multiplicity of tongue tumors were $30 \%$ and $0.45 \pm 0.83$ in the TSOD mice and $30 \%$ and $0.40 \pm 0.68$ in the TSNO mice. The incidence and multiplicity of esophageal tumors were $70 \%$ and $2.25 \pm 2.29$ in the TSOD mice and $30 \%$ and $0.60 \pm 1.14(\mathrm{P}<0.01)$ in the TSNO mice.

Conclusion: Our findings indicate that the obese and diabetic TSOD mice were susceptible to 4-NQO-induced esophageal carcinogenesis, suggesting risk factors of obese and diabetes for esophageal squamous cell carcinoma. Additionally, the TSOD mice were useful as esophagus carcinogenic model. Our study first reported that 4-NQO induced esophageal cancer in mice.

Keywords: Obesity; Diabetes; Oral carcinogenesis; Esophageal carcinogenesis; 4-nitroquinoline 1-oxide; TSOD mice; TSNO mice

\section{Introduction}

Obesity and type 2 diabetes mellitus are risk factors for cancer development at several tissues [1-5] and cardiovascular diseases [6-9]. Currently, the prevalence of type 2 diabetes has increased significantly in developed countries [10]. Animal models of spontaneous obese and type 2 diabetes have been reported and contributed to studies on human diabetic syndromes [11-13] and an association between obesity/diabetes and carcinogenesis [14-16]. They include NSY mice and KK-Ay mice that are mild obese, hyperglycemic and hyperinsulinemia [17-19]. Massive obesity mice, C57BL/6J-Lee (ob/ob) mice lack leptin and show mild hyperglycemia and hyperinsulinemia. These mice revert to normal glycemia at 7 months of age [17, 20, 21]. C57BL6/KsJ + Leprdb $(d b / d b)$ mice with mutations impairing leptin receptor signaling have severe hyperglycemia, hyperinsulinemia and obesity as early as 10 days of age [22-24]. At $4-5$ months of age, the animal became more severely hyperglycemic with hypoinsulinemia, 
weight loss and early death $[17,20,25]$. In addition, a relatively new polygenetic model of spontaneous obese type 2 diabetes mellitus mice named as Tsumura Suzuki obese diabetes (TSOD) mice, has been established as an inbred line in 1992 and the clinical symptoms of diabetes have been characterized by Suzuki et al [26]. Male TSOD mice constantly showed signs of obesity and urinary sugar with increased intake of food and heavy body and fat weights. Blood glucose and insulin levels are constantly high during their life [26, 27]. Carcinogenesis using KK-Ay mice [28-30], ob/ob mice $[31,32]$, and $\mathrm{db} / \mathrm{db}$ mice $[33,34]$ was well studied to determine an association between obesity/diabetes and oncogenesis. However, carcinogenesis in the TSOD mice has not yet been reported.

In this study, we first evaluated oncogenesis in the male TSOD mice in comparison with the Tsumura Suzuki non-obesity (TSNO, non-diabetic control) mice. A chemical carcinogen, 4-nitroquinoline 1-oxide (4-NQO), was used to produce tumors in the tongue and esophagus. Furthermore, we examined the expression of several proinflammatory cytokines and inflammatory enzymes in the target tissues.

\section{Materials and Methods}

\section{Animals, diet and carcinogen}

Twenty-eight male TSOD and 28 TSNO mice at 8 weeks of age used in this study were purchased from the Institute for Animal Reproduction (Ibaraki, Japan). Four mice were housed in a plastic cage in a non-barrier-sustained animal room maintained at $23 \pm 2{ }^{\circ} \mathrm{C}$ with $50 \pm 10 \%$ humidity and a $12 / 12 \mathrm{~h} \mathrm{light/}$ dark cycle. They were maintained on a basal diet MF (Oriental Yeast Co., Ltd, Tokyo) and tap water ad libitum. All animal experiments were approved and carried out following the Guideline for Animal Experimentation of Gifu University. 4-NQO (98\% pure, CAS no. 56-57-5, Wako Pure Chemical Ind., Osaka, Japan) was used as a carcinogen to induce tongue and/or esophageal tumors in this study.

\section{Treatments}

TSOD and TSNO mice were divided into two groups, respectively. One group $(n=20)$ was treated with $4-\mathrm{NQO}(98 \%$ pure, CAS no. 56-57-5, Wako Pure Chemical Ind., Osaka, Japan) in drinking water for 8 weeks at a concentration of $20 \mathrm{ppm}$, and then the mice were given tap water without 4-NQO for 20 weeks. The other group $(\mathrm{n}=8)$ was given tap water without 4-NQO throughout the experimental period. At week 28, all mice were sacrificed and complete necropsy was done on all mice.

\section{Measurement of biochemical parameters}

At sacrifice, the blood samples were collected and centrifuged to obtain plasma samples to be determined. Concentrations of the following determinants were assayed using a Model 680 microplate reader (BIO-RAD Laboratories, CA, USA) with a kit for each substance: levels of plasma glucose (Glucose CII-Test; Wako Pure Chemical Industries, Osaka, Japan), total cholesterol (T-Cho) (Cholesterol E-Test; Wako Pure Chemical Industries), triglyceride (Triglyceride E-Test; Wako Pure Chemical Industries), high-density lipoprotein (HDL)-cholesterol (HDL-cholesterol E-Test; Wako Pure Chemical Industries) and low-density lipoprotein (LDL)-cholesterol (Cholestest LDL; Daiichi Pure Chemicals, Tokyo, Japan).

\section{Histopathology}

The animals were sacrificed at 28 weeks to evaluate the occurrence of preneoplasms and neoplasms in both the tongue and esophagus. At killing by exsanguination under a deep ether anesthesia, macroscopic examination was carefully performed and the numbers of grossly visible tumors in the tongue and esophagus were counted, and then these tissues with or without tumors were processed for histopathological examination after being fixed in $10 \%$ buffered formalin. For a histological examination, the tissues fixed in $10 \%$ buffered formalin were embedded in paraffin block, and then the histological sections were stained with hematoxylin and eosin.

Epithelial lesions (dysplasia and neoplasia) in both tissues were diagnosed according to our previous study [35]. To determine the multiplicity of the tongue and esophageal lesions, the tissue specimens were examined for gross lesions without the use of any magnification aid.

\section{A short-term experiment to measure esophageal cytokines and chemokines}

Sixteen male TSOD ( 8 weeks old) and 16 male TSNO mice (8 weeks old) were obtained from the Institute for Animal Reproduction. They were given tap water with or without 20 ppm 4-NQO for 8 weeks. At 8 weeks after the start of the experiment, the esophagus with or without lesions was processed to assay the content of cytokines (Mouse TNF- $\alpha$ Quantikine ELISA Kit, Cat \# PMTA008; Mouse Quantikine IL-1 $\beta$ ELISA Kit, Cat \# SMLB00C; Mouse IFN- $\gamma$ Quantikine ELISA Kit, Cat \# SMIF00; Mouse IL-6 Quantikine ELISA Kit, Cat \# PM6000B; and Mouse IL-17 Quantikine ELISA Kit, Cat \# PM1700) and chemokines (Mouse CXCL1/KC Quantikine ELISA Kit, Cat \# PMKC0B; Mouse CCL3/MIP-1 $\alpha$ Quantikine ELISA Kit, Cat \# PMMA00; and Mouse CXCL2/ MIP-2 Quantikine ELISA Kit, Cat \# MM200) using the R\&D Systems ELISA kits (R\&D Systems, Inc., Minneapolis, MN, USA), which was obtained from Funakoshi Co., Ltd (Tokyo, Japan).

To quantify esophageal tissue cytokines and chemokines, $50 \mathrm{mg}$ of esophageal tissue was extracted using $500 \mu \mathrm{L}$ of $5 \mathrm{M}$ guanidine $\mathrm{HCl}$ and $50 \mathrm{mM}$ Tris- $\mathrm{HCl}(\mathrm{pH} 8.0)$ with a protease inhibitor. The extracts were centrifuged at $15,000 \mathrm{~g}$ for $30 \mathrm{~min}$ at $4{ }^{\circ} \mathrm{C}$ to remove insoluble materials. Levels of TNF- $\alpha$, IL-1 $\beta$, IFN- $\gamma$, IL-6, IL-17, KC, MIP- $1 \alpha$ and MIP-2 in the supernatant 
Table 2. Clinical Chemistry

\begin{tabular}{|c|c|c|c|c|}
\hline & & mice & & mice \\
\hline & 4-NQO & None & 4-NQO & None \\
\hline Glucose (mg/dL) & $171 \pm 29^{\mathrm{a}}$ & $135 \pm 19$ & $90 \pm 21$ & $102 \pm 13$ \\
\hline Triglyceride (mg/dL) & $233 \pm 39$ & $113 \pm 61$ & $33.6 \pm 4.6$ & $16.4 \pm 3.5$ \\
\hline Total cholesterol (mg/dL) & $227 \pm 22$ & $183 \pm 46$ & $137 \pm 13$ & $121 \pm 12$ \\
\hline HDL-cholesterol (mg/dL) & $116 \pm 20$ & $107 \pm 13$ & $160 \pm 16$ & $139 \pm 20$ \\
\hline LDL-cholesterol (mg/dL) & $37.8 \pm 9.1$ & $24.0 \pm 11.2$ & $12.2 \pm 1.3$ & $18.8 \pm 4.7$ \\
\hline
\end{tabular}

aMean \pm SD.

fractions were determined by sandwich ELISA using the kits from R\&D Systems, Inc. ELISA was performed according to the manufacturer's instructions. To quantify, the 1:20 dilutions of the supernatants of esophageal tissue homogenates were added into 96-well microplates. These microplates were coated with polyclonal goat anti-mouse cytokine or chemokine antibodies, which were used as capturing antibodies and biotinylated polyclonal rabbit anti-mouse cytokine antibodies for detection. Streptavidin-HRP and tetramethylbenzidine sulfonate were added as color indicators. Plates were read at $490 \mathrm{~nm}$ immediately after the color reaction was stopped with acid. Standard curves were prepared like the samples using diluted standard solutions. All standards and samples were run triplicate.

\section{Statistical analysis}

The Fisher's exact probability test was used for statistical analysis of the incidence of lesions. The other results expressed as the mean $\pm \mathrm{SD}$ were analyzed by Student-Newman-Keuls multiple comparison test using the GraphPad InStat software (version 3.05, GraphPad Software, San Diego, CA). A level of $\mathrm{P}<0.05$ was considered to be statistically significant.

\section{Results}

\section{Body, liver and visceral fat weights}

Mean body weight of the TSOD mice with or without 4-NQO treatment at the end of study was significantly heavier than that of the TSNO mice with or without 4-NQO exposure, as shown in Table 1. Similarly, mean weight of visceral (epididymal, mesenteric, retroperitoneal and perinephric) fat in the TSOD mice with or without 4-NQO treatment was significantly heavier than that of TSNO mice with or without 4-NQO exposure.

\section{Biochemistry in the serum}

As listed in Table 2, the values of serum glucose, triglyceride, total cholesterol, HDL and LDL in the TSOD mice were higher than those of TSNO mice regardless of the treatment of 4-NQO.

\section{Incidence and multiplicity of proliferative lesions in the tongue and esophagus}

4-NQO treatment induced proliferative lesions in the tongue and esophagus of TSOD and TSNO mice. Proliferative lesions developed in the tongue (Fig. 1) and esophagus (Fig. 2) included squamous cell dysplasia, papilloma and carcinomas. The incidences and multiplicities are summarized in Tables 3 and 4 . The incidence and multiplicities of tongue proliferative lesions were comparable in the TSOD and TSNO mice (Table $3)$. On the other hand, the incidences of squamous cell papilloma $(60 \%)$ and carcinoma $(50 \%)$ in the esophagus of TSOD mice were significantly larger than those $(30 \%$ and $0 \%)$ of TSNO mice when both types of mice were given 4-NQO (Table 4$)$. In addition, the multiplicity $(1.50 \pm 1.70)$ of esophageal squamous cell papilloma in the TSOD mice given 4-NQO was significantly higher than that $(0.60 \pm 1.14)$ of TSNO mice that

Table 1. Body, Liver and Visceral Fat Weights

\begin{tabular}{|c|c|c|c|c|}
\hline \multirow{2}{*}{ Treatment } & \multicolumn{2}{|c|}{ TSOD mice } & \multicolumn{2}{|c|}{ TSNO mice } \\
\hline & $4-\mathrm{NQO}(\mathrm{n}=20)$ & None $(n=8)$ & 4-NQO $(n=20)$ & None $(n=8)$ \\
\hline \multicolumn{5}{|l|}{ Body weight (g) } \\
\hline Initial & $35.1 \pm 1.2 \mathrm{a}$ & $35.4 \pm 2.0$ & $23.6 \pm 2.2$ & $25.1 \pm 1.7$ \\
\hline Final & $63.3 \pm 2.2$ & $64.5 \pm 2.7$ & $43.5 \pm 2.1$ & $45.4 \pm 2.1$ \\
\hline Liver weight (g) & $1.64 \pm 0.12$ & $1.59 \pm 0.20$ & $1.48 \pm 0.17$ & $1.52 \pm 0.14$ \\
\hline Visceral fat weight $^{\mathrm{b}}(\mathrm{g})$ & $5.52 \pm 0.21$ & $5.62 \pm 0.19$ & $1.39 \pm 0.17$ & $1.59 \pm 0.21$ \\
\hline
\end{tabular}

a. Mean \pm SD. bVisceral fat includes epididymal, mesenteric, retroperitoneal and perinephric fats. 

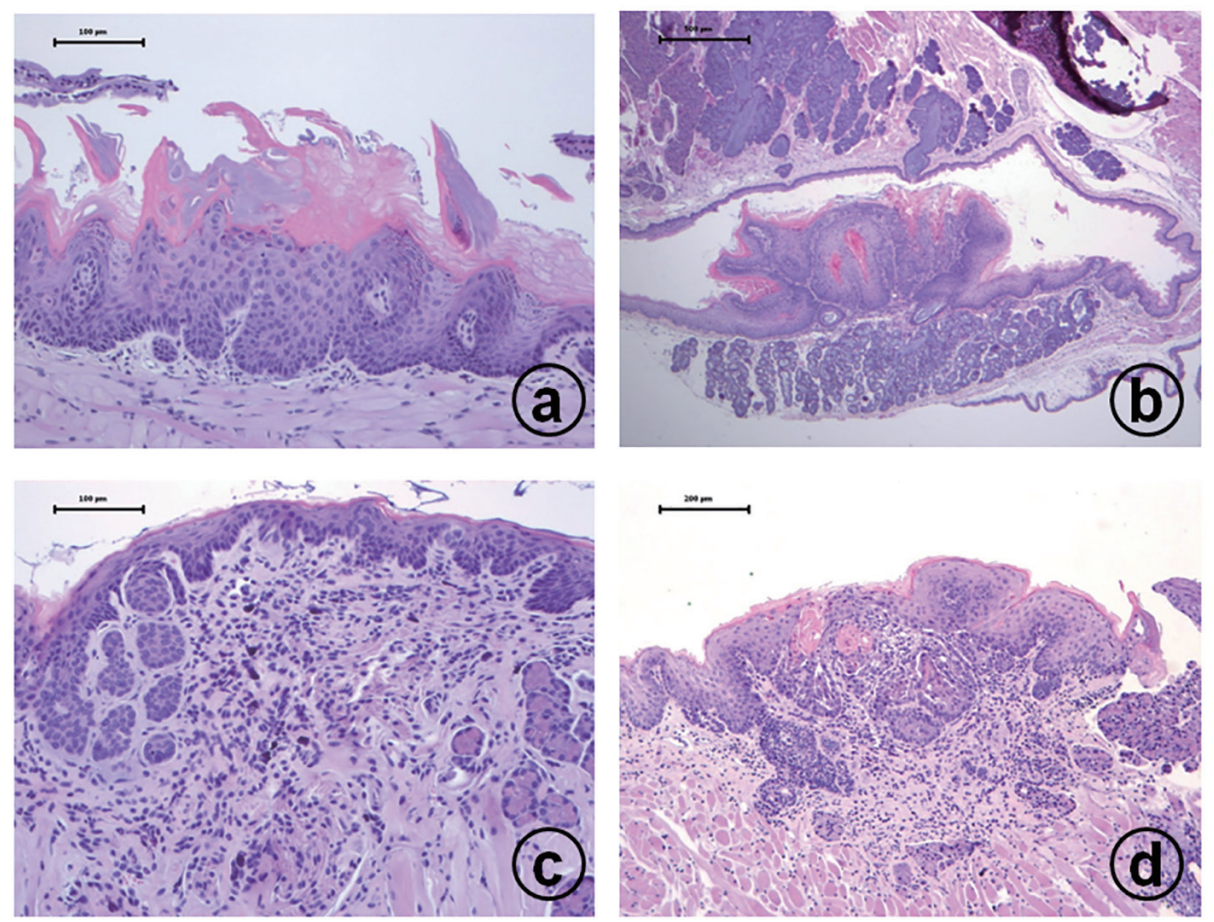

Figure 1. Histopathology of tongue proliferative lesions developed in male TSOD mice treated with 20 ppm 4-NQO in drinking water: (a) moderate dysplasia; (b) squamous cell papilloma; (c) carcinoma in situ; (d) invasive squamous cell carcinoma. Hematoxylin and eosin stain, bar $=100 \mu \mathrm{m}$.
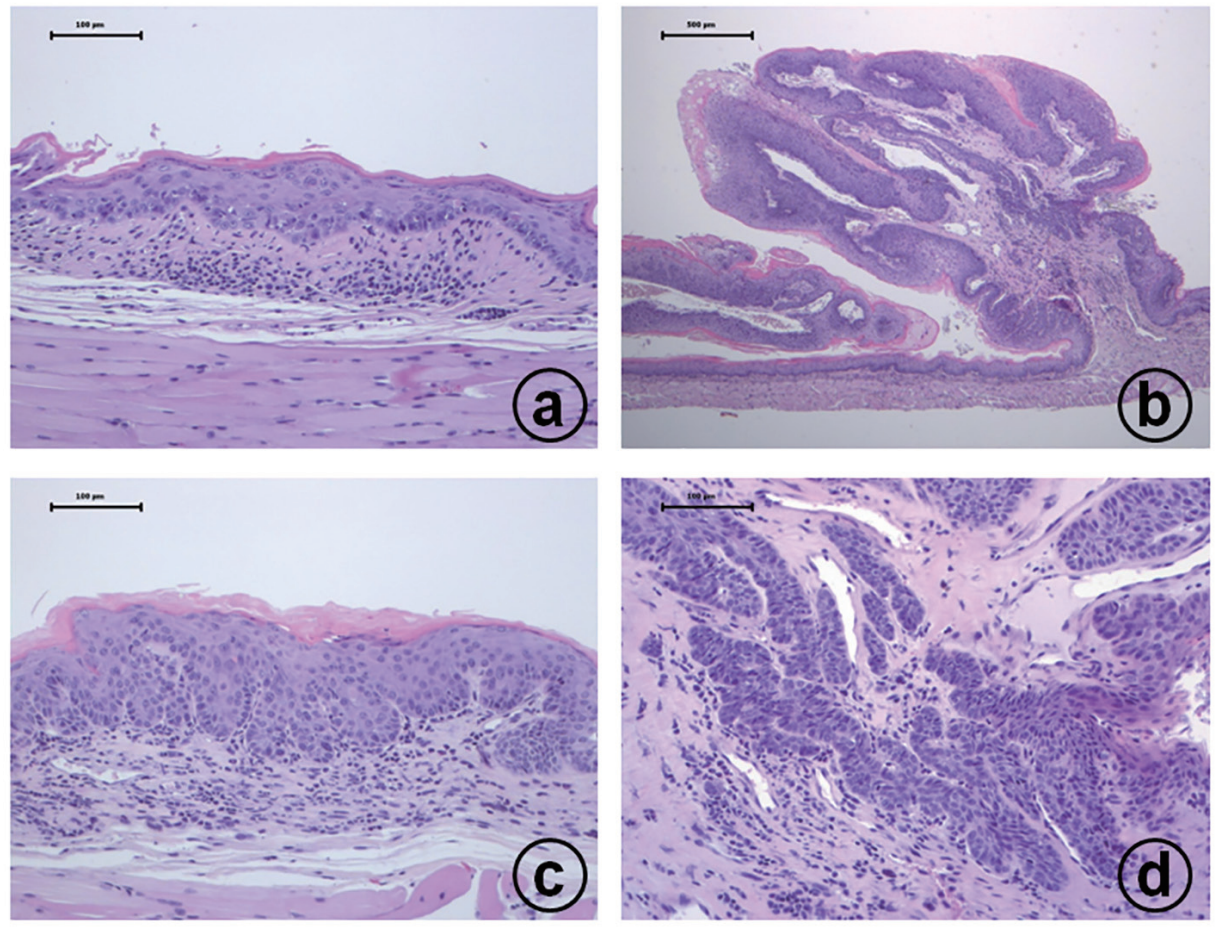

Figure 2. Histopathology of esophageal proliferative lesions in male TSOD mice treated with 20 ppm 4-NQO in drinking water: (a) moderate dysplasia; (b) squamous cell papilloma; (c) carcinoma in situ; (d) invasive squamous cell carcinoma. Hematoxylin and eosin stain, bar $=100 \mu \mathrm{m}$. 
Table 3. Tongue Proliferative Lesions

\begin{tabular}{llllll}
\hline \multirow{2}{*}{ Lesions } & \multicolumn{2}{c}{ TSOD mice treated with 4-NQO } & & \multicolumn{2}{c}{ TSNO mice treated with 4-NQO } \\
\cline { 2 - 3 } \cline { 5 - 6 } & Incidence (\%) & Multiplicity (no. of lesions/mouse) & & Incidence (\%) & Multiplicity (no. of lesions/mouse) \\
\hline Dysplasia & 100 & $4.80 \pm 1.44^{\mathrm{a}}$ & & 100 & $3.95 \pm 1.47$ \\
Papilloma & 15 & $0.20 \pm 0.52$ & 10 & $0.10 \pm 0.31$ \\
Squamous cell carcinoma & 20 & $0.30 \pm 0.66$ & 25 & $0.30 \pm 0.57$ \\
Total tumors & 30 & $0.50 \pm 0.89$ & 30 & $0.40 \pm 0.68$ \\
\hline
\end{tabular}

aMean \pm SD.

received 4-NQO (Table 4).

\section{TNF- $\alpha$, IL-1 $\beta$, IFN- $\gamma$, IL-6, IL-17, KC, MIP-1 $\alpha$ and MIP-2 protein expression by ELISA}

ELISA assays were conducted to determine the levels of TNF- $\alpha$, IL- $1 \beta$, IFN- $\gamma$, IL-6, IL-17, KC, MIP-1 $\alpha$ and MIP2 protein expression in the esophagus (Fig. 3). In the TSOD mice, the expression of all the proteins (Fig. 3a-g) except MIP2 (Fig. 3h) was significantly increased when 4-NQO was administered $(\mathrm{P}<0.001, \mathrm{P}<0.01$ or $\mathrm{P}<0.05)$. In the TSNO mice, the expression of all the proteins (Fig. 3a-e, g), except KC (Fig. 3f) and MIP-2 (Fig. 3h), was significantly elevated when 4-NQO was administered $(\mathrm{P}<0.001, \mathrm{P}<0.01$ or $\mathrm{P}<$ $0.05)$. When compared with the TSNO mice given 4-NQO, the expression of TNF- $\alpha$ protein (Fig. 3a) was significantly upregulated in the TSOD mice that received 4-NQO $(\mathrm{P}<0.01)$.

\section{Discussion}

Obesity and type 2 diabetes mellitus are risk factors of cancer development, including oral and esophageal cancers [24, 3644]. As to esophageal cancer, esophageal adenocarcinoma, but not squamous cell carcinoma, is closely related to obesity [36]. In the current study, we demonstrated that development of esophageal squamous cell carcinoma is associated with obesity and diabetes mellitus. However, in this study, we did not show an association between oral squamous cell carcinoma and obesity/diabetes mellitus. The reason for this is unknown, but we would speculate that carcinogenic stimuli of 4-NQO are too strong in the oral cavity. Dixon et al [45] have recently reported an association between diabetes mellitus development of adenocarcinoma in the esophagus and gastric cardia, and the association was independent of obesity [45].

Analysis of clinical chemistry in the current study showed the TSOD mice are obese, diabetic, hypertriglyceridemia and hyperlipidemia, when compared with the TSNO mice. Hyperlipidemia is reported to be a risk for developing oral cancer [38] and lymph node metastasis of esophageal cancer [46]. In our study, we did not observe distant metastases of tongue and esophageal cancers in TSOD and TSNO mice. However, the numbers of oral and esophageal tumors per animal in the TSOD mice that received 4-NQO were higher than those of TSNO mice given 4-NQO.

In the current study, we found that 4-NQO-induced carcinogenesis in the TSOD mice was susceptible in the esophagus when compared with the tongue. The exact mechanism(s) for the findings are not known, but our analysis indicated that several pro-inflammatory cytokines and chemokines in the esophagus of the TSOD mice that received 4-NQO were highly expressed when compared with the TSNO mice. Both tumor-inhibiting and tumor-enhancing inflammatory cells can be found in neoplastic lesions in several tissues, including oral cavity and esophagus [47-49]. Inflammation could increase the risk of cancer development by providing bioactive molecules, such as cytokines and chemokines, from cells that infiltrate the tumor microenvironment [50]. The role of several inflammatory mediators in events of carcinogenesis includes their capability to generate reactive oxygen and nitrogen species; their potential mutagenic effects; and involvement in mechanisms for epithelial-mesenchymal transition, angiogenesis, and metastasis.

We observed tongue and esophageal dysplasia as well as neoplasms in the TSOD and TSNO mice that received drinking water containing 4-NQO. Squamous cell dysplasia is a precursor lesion for oral [51] and esophageal squamous cell carcinoma [52]. Although there are a few animal models of oral-esophageal cancer [53-55], TNOD mice are suitable for understanding and analyzing an association between obesity/

Table 4. Esophageal Proliferative Lesions

\begin{tabular}{llllll}
\hline \multirow{2}{*}{ Lesions } & \multicolumn{2}{c}{ TSOD mice treated with 4-NQO } & & \multicolumn{2}{c}{ TSNO mice treated with 4-NQO } \\
\cline { 2 - 3 } \cline { 5 - 6 } & Incidence (\%) & Multiplicity (no. of lesions/mouse) & & Incidence (\%) & Multiplicity (no. of lesions/mouse) \\
\hline Dysplasia & 100 & $6.55 \pm 1.73^{\mathrm{a}}$ & 100 & $6.75 \pm 3.32$ \\
Papilloma & $60^{\mathrm{b}}$ & $1.50 \pm 1.70^{\mathrm{b}}$ & 30 & $0.60 \pm 1.14$ \\
Squamous cell carcinoma & $50^{\mathrm{c}}$ & $0.75 \pm 0.91$ & 30 & 0 \\
Total tumors & 70 & $2.25 \pm 2.29^{\mathrm{d}}$ & & $0.60 \pm 1.14$ \\
\hline
\end{tabular}

${ }^{a}$ Mean \pm SD. ${ }^{b-d}$ Significantly different from the values of the TSNO mice treated with 4-NQO $\left({ }^{b} P<0.05,{ }^{c} P<0.001\right.$, and $\left.{ }^{d} P<0.01\right)$. 


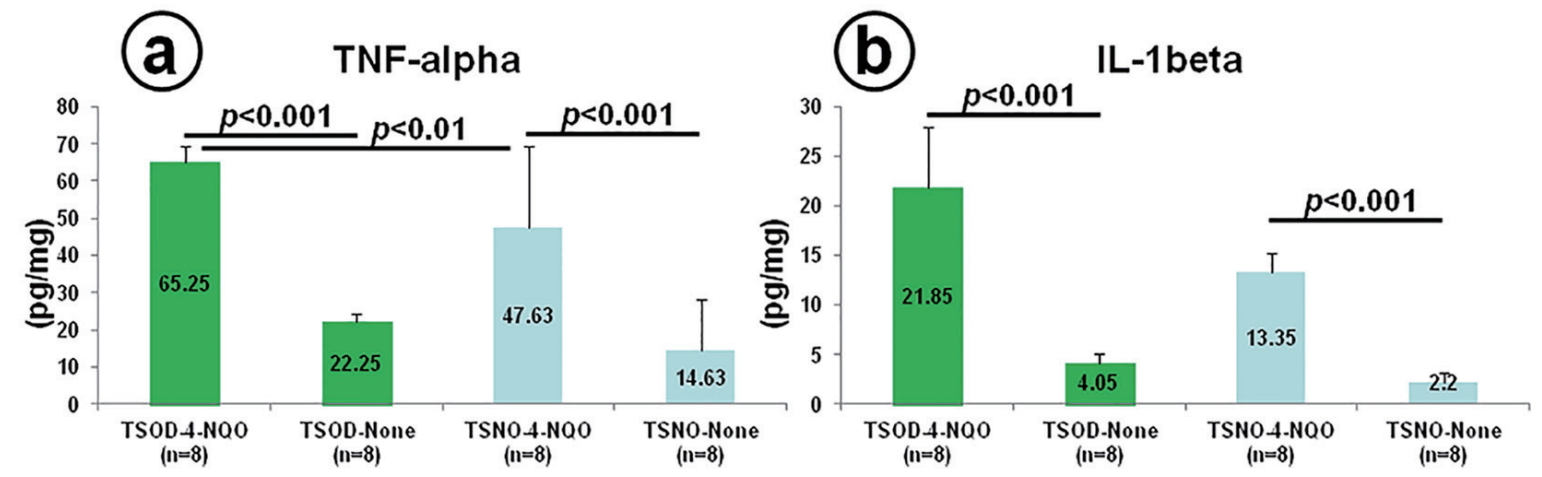

(c)

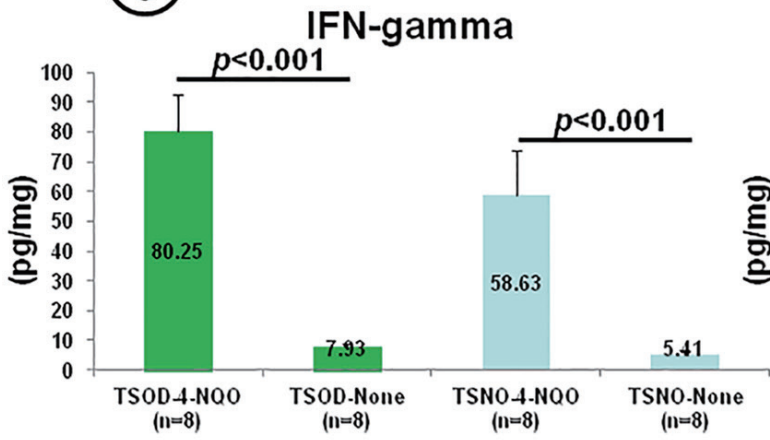

(d)
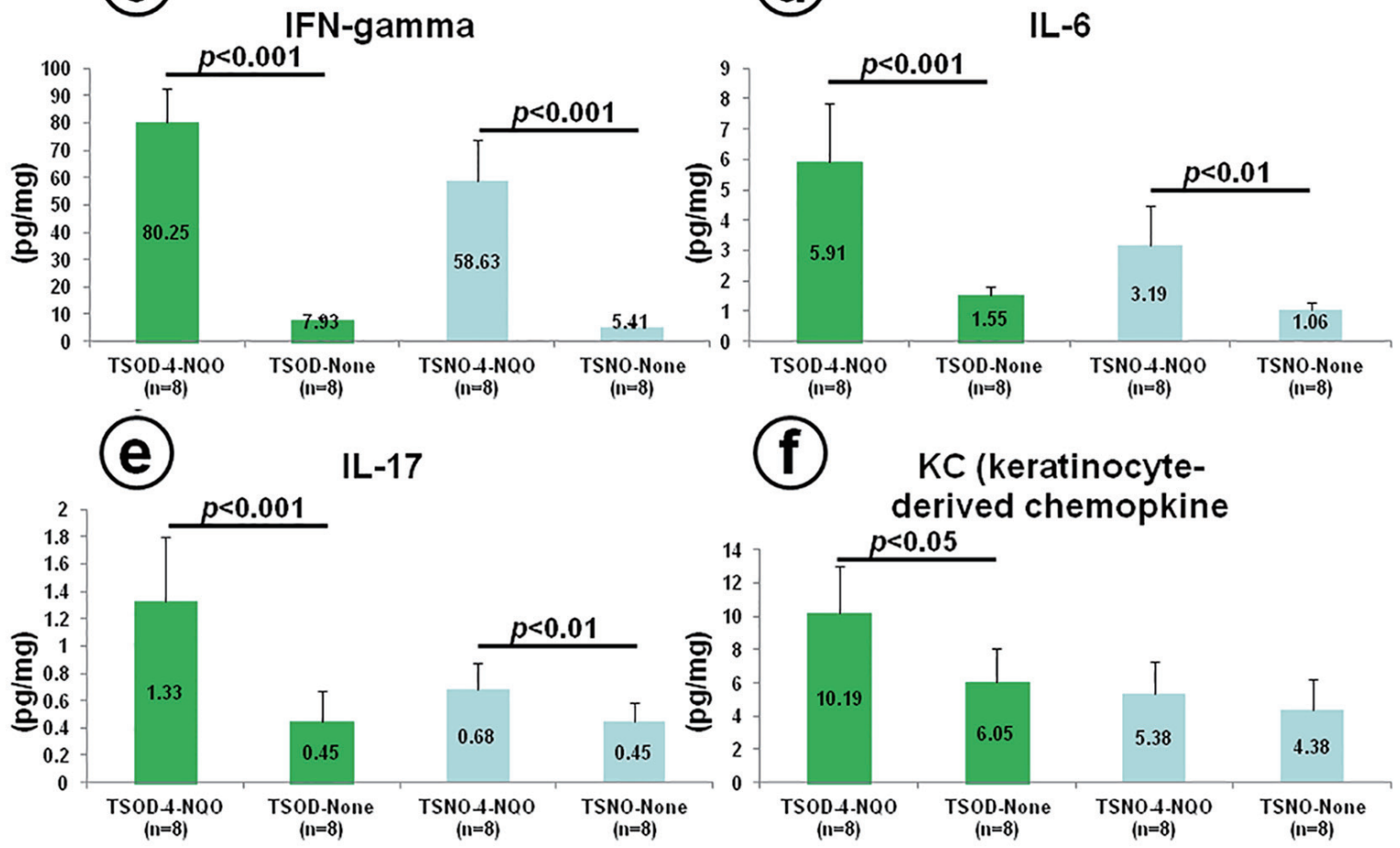

KC (keratinocyte-

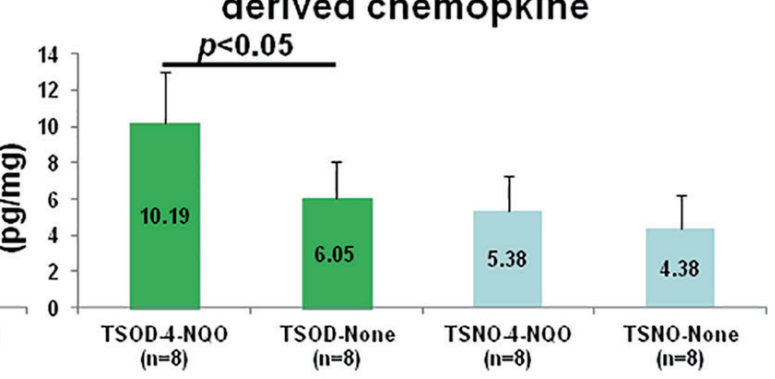

(9)

MIP-1alpha

(Macrophage inflammatory

protein 1)

MIP-2

(Macrophage inflammatory

protein 2)

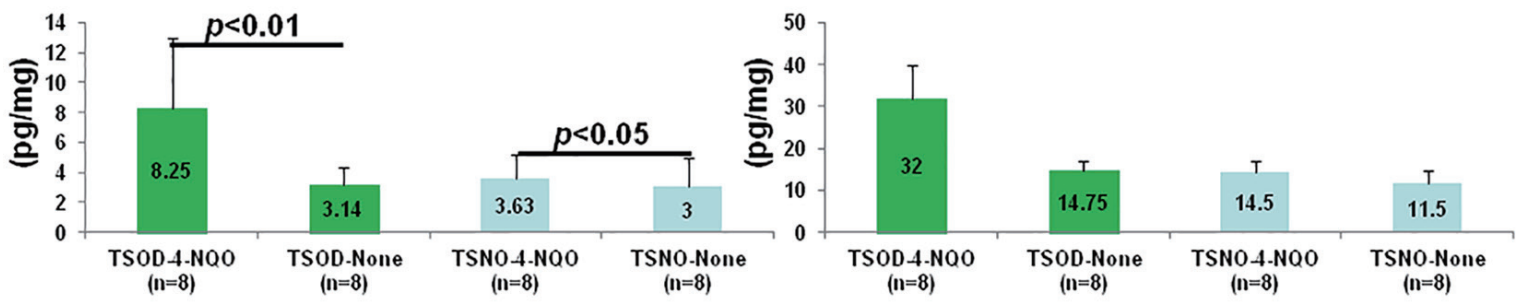

Figure 3. Measures of esophageal cytokines and chemokines in a short-term experiment using 16 male TSOD and 16 male TSNO mice given tap water with or without 20 ppm 4-NQO for 8 weeks. At 8 weeks after the start of the experiment: (a) TNF- $\alpha$, (b) IL-1 $\beta$, (c) IFN- $\gamma$, (d) IL-6, (e) IL-17, (f) CXCL1/KC, (g) CCL3/MIP-1 $\alpha$, and (h) CXCL2/MIP-2. 
diabetes and esophageal carcinogenesis when used a carcinogen 4-NQO. Also, involvement of inflammatory stimuli in oncogenesis in these tissues can be investigated. Our future studies include basic research of chemoprevention of oral and esophageal squamous cell carcinogenesis.

\section{Acknowledgments}

The study was supported by the TSOD Mouse Research Fund.

\section{Competing Interests}

We declare that they have no competing interests.

\section{References}

1. Aleman JO, Eusebi LH, Ricciardiello L, Patidar K, Sanyal AJ, Holt PR. Mechanisms of obesity-induced gastrointestinal neoplasia. Gastroenterology. 2014;146(2):357373.

2. Bao B, Wang Z, Li Y, Kong D, Ali S, Banerjee S, Ahmad A, et al. The complexities of obesity and diabetes with the development and progression of pancreatic cancer. Biochim Biophys Acta. 2011;1815(2):135-146.

3. Gristina V, Cupri MG, Torchio M, Mezzogori C, Cacciabue L, Danova M. Diabetes and cancer: A critical appraisal of the pathogenetic and therapeutic links. Biomed Rep. 2015;3(2):131-136.

4. Goto A, Noto H, Noda M, Ueki K, Kasuga M, Tajima N, Ohashi K, et al. Report of the Japan diabetes society/Japanese cancer association joint committee on diabetes and cancer, Second report. Cancer Sci. 2016;107(3):369-371.

5. Noto H, Goto A, Tsujimoto T, Osame K, Noda M. Latest insights into the risk of cancer in diabetes. J Diabetes Investig. 2013;4(3):225-232.

6. Kannel WB, Hjortland M, Castelli WP. Role of diabetes in congestive heart failure: the Framingham study. Am J Cardiol. 1974;34(1):29-34.

7. Nichols GA, Hillier TA, Erbey JR, Brown JB. Congestive heart failure in type 2 diabetes: prevalence, incidence, and risk factors. Diabetes Care. 2001;24(9):1614-1619.

8. Ellulu MS. Obesity, cardiovascular disease, and role of vitamin $\mathrm{C}$ on inflammation: a review of facts and underlying mechanisms. Inflammopharmacology. 2017;25(3):313328.

9. Rippe JM, Angelopoulos TJ. Added sugars and risk factors for obesity, diabetes and heart disease. Int $\mathrm{J}$ Obes (Lond). 2016;40(Suppl 1):S22-27.

10. Hu FB. Globalization of diabetes: the role of diet, lifestyle, and genes. Diabetes Care. 2011;34(6):1249-1257.

11. Arakawa K, Ishihara T, Oku A, Nawano M, Ueta K, Kitamura K, Matsumoto M, et al. Improved diabetic syndrome in $\mathrm{C} 57 \mathrm{BL} / \mathrm{KsJ}-\mathrm{db} / \mathrm{db}$ mice by oral administration of the $\mathrm{Na}(+)$-glucose cotransporter inhibitor $\mathrm{T}-1095$. Br J Pharmacol. 2001;132(2):578-586.

12. Guberski DL, Butler L, Manzi SM, Stubbs M, Like AA.
The BBZ/Wor rat: clinical characteristics of the diabetic syndrome. Diabetologia. 1993;36(10):912-919.

13. Weiss H, Bleich A, Hedrich HJ, Kolsch B, Elsner M, Jorns A, Lenzen S, et al. Genetic analysis of the LEW.1AR1iddm rat: an animal model for spontaneous diabetes mellitus. Mamm Genome. 2005;16(6):432-441.

14. Hirose Y, Hata K, Kuno T, Yoshida K, Sakata K, Yamada Y, Tanaka T, et al. Enhancement of development of azoxymethane-induced colonic premalignant lesions in C57BL/ $\mathrm{KsJ}-\mathrm{db} / \mathrm{db}$ mice. Carcinogenesis. 2004;25(5):821-825.

15. Ngo HT, Hetland RB, Nygaard UC, Steffensen IL. Genetic and diet-induced obesity increased intestinal tumorigenesis in the double mutant mouse model multiple intestinal neoplasia X obese via disturbed glucose regulation and inflammation. J Obes. 2015;2015:343479.

16. Teraoka N, Mutoh M, Takasu S, Ueno T, Nakano K, Takahashi M, Imai T, et al. High susceptibility to azoxymethane-induced colorectal carcinogenesis in obese KK-Ay mice. Int J Cancer. 2011;129(3):528-535.

17. Mordes JP, Rossini AA. Animal models of diabetes. Am J Med. 1981;70(2):353-360.

18. Ueda H, Ikegami H, Yamato E, Fu J, Fukuda M, Shen G, Kawaguchi Y, et al. The NSY mouse: a new animal model of spontaneous NIDDM with moderate obesity. Diabetologia. 1995;38(5):503-508.

19. Alpers CE, Hudkins KL. Mouse models of diabetic nephropathy. Curr Opin Nephrol Hypertens. 2011;20(3):278284.

20. Coleman DL, Hummel KP. Studies with the mutation, diabetes, in the mouse. Diabetologia. 1967;3(2):238-248.

21. Genuth SM, Przybylski RJ, Rosenberg DM. Insulin resistance in genetically obese, hyperglycemic mice. Endocrinology. 1971;88(5):1230-1238.

22. Ktorza A, Bernard C, Parent V, Penicaud L, Froguel P, Lathrop M, Gauguier D. Are animal models of diabetes relevant to the study of the genetics of non-insulin-dependent diabetes in humans? Diabetes Metab. 1997;23(Suppl 2):38-46.

23. Samad F, Loskutoff DJ. The fat mouse: a powerful genetic model to study elevated plasminogen activator inhibitor 1 in obesity/NIDDM. Thromb Haemost. 1997;78(1):652655.

24. Tesch GH, Lim AK. Recent insights into diabetic renal injury from the $\mathrm{db} / \mathrm{db}$ mouse model of type 2 diabetic nephropathy. Am J Physiol Renal Physiol. 2011;300(2):F301-310.

25. Coleman DL. Diabetes-obesity syndromes in mice. Diabetes. 1982;31(Suppl 1 Pt 2):1-6.

26. Suzuki W, Iizuka S, Tabuchi M, Funo S, Yanagisawa T, Kimura M, Sato T, et al. A new mouse model of spontaneous diabetes derived from ddY strain. Exp Anim. 1999;48(3):181-189.

27. Iizuka S, Suzuki W, Tabuchi M, Nagata M, Imamura S, Kobayashi Y, Kanitani M, et al. Diabetic complications in a new animal model (TSOD mouse) of spontaneous NIDDM with obesity. Exp Anim. 2005;54(1):71-83.

28. Ito K, Ishigamori R, Mutoh M, Ohta T, Imai T, Takahashi M. Ay allele promotes azoxymethane-induced colorectal carcinogenesis by macrophage migration in hyperlipi- 
demic/diabetic KK mice. Cancer Sci. 2013;104(7):835843.

29. Komiya M, Fujii G, Miyamoto S, Takahashi M, Ishigamori R, Onuma W, Ishino K, et al. Suppressive effects of the NADPH oxidase inhibitor apocynin on intestinal tumorigenesis in obese KK-A(y) and Apc mutant Min mice. Cancer Sci. 2015;106(11):1499-1505.

30. Ueno T, Teraoka N, Takasu S, Nakano K, Takahashi M, Yamamoto M, Fujii G, et al. Suppressive effect of pioglitazone, a PPAR gamma ligand, on azoxymethaneinduced colon aberrant crypt foci in KK-Ay mice. Asian Pac J Cancer Prev. 2012;13(8):4067-4073.

31. Mentor-Marcel RA, Bobe G, Barrett KG, Young MR, Albert PS, Bennink MR, Lanza E, et al. Inflammationassociated serum and colon markers as indicators of dietary attenuation of colon carcinogenesis in ob/ob mice. Cancer Prev Res (Phila). 2009;2(1):60-69.

32. Zhang Y, Ge X, Heemstra LA, Chen WD, Xu J, Smith JL, $\mathrm{Ma} \mathrm{H}$, et al. Loss of FXR protects against diet-induced obesity and accelerates liver carcinogenesis in ob/ob mice. Mol Endocrinol. 2012;26(2):272-280.

33. Suzuki R, Kohno H, Yasui Y, Hata K, Sugie S, Miyamoto S, Sugawara K, et al. Diet supplemented with citrus unshiu segment membrane suppresses chemically induced colonic preneoplastic lesions and fatty liver in male $\mathrm{db} / \mathrm{db}$ mice. Int J Cancer. 2007;120(2):252-258.

34. Tanaka T, Yasui Y, Ishigamori-Suzuki R, Oyama T. Citrus compounds inhibit inflammation- and obesity-related colon carcinogenesis in mice. Nutr Cancer. 2008;60(Suppl 1):70-80.

35. Miyamoto S, Yasui Y, Kim M, Sugie S, Murakami A, Ishigamori-Suzuki R, Tanaka T. A novel rasH2 mouse carcinogenesis model that is highly susceptible to 4-NQOinduced tongue and esophageal carcinogenesis is useful for preclinical chemoprevention studies. Carcinogenesis. 2008;29(2):418-426.

36. Duggan C, Onstad L, Hardikar S, Blount PL, Reid BJ, Vaughan TL. Association between markers of obesity and progression from Barrett's esophagus to esophageal adenocarcinoma. Clin Gastroenterol Hepatol. 2013;11(8):934-943.

37. Tilg H, Moschen AR. Mechanisms behind the link between obesity and gastrointestinal cancers. Best Pract Res Clin Gastroenterol. 2014;28(4):599-610.

38. Tseng KS, Lin C, Lin YS, Weng SF. Risk of head and neck cancer in patients with diabetes mellitus: a retrospective cohort study in Taiwan. JAMA Otolaryngol Head Neck Surg. 2014;140(8):746-753.

39. Yamada T, Hara K, Kadowaki T. Chewing betel quid and the risk of metabolic disease, cardiovascular disease, and all-cause mortality: a meta-analysis. PLoS One. 2013;8(8):e70679.

40. Acosta A, Streett S, Kroh MD, Cheskin LJ, Saunders KH, Kurian M, Schofield M, et al. White Paper AGA: POWER - practice guide on obesity and weight management, education, and resources. Clin Gastroenterol Hepatol. 2017;15(5):631-649 e610.
41. Bosetti C, Rosato V, Polesel J, Levi F, Talamini R, Montella M, Negri E, et al. Diabetes mellitus and cancer risk in a network of case-control studies. Nutr Cancer. 2012;64(5):643-651.

42. Gong Y, Wei B, Yu L, Pan W. Type 2 diabetes mellitus and risk of oral cancer and precancerous lesions: a meta-analysis of observational studies. Oral Oncol. 2015;51(4):332-340.

43. Huang W, Ren H, Ben Q, Cai Q, Zhu W, Li Z. Risk of esophageal cancer in diabetes mellitus: a meta-analysis of observational studies. Cancer Causes Control. 2012;23(2):263-272.

44. Vegh D, Banyai D, Hermann P, Nemeth Z, Ujpal M. Type-2 diabetes mellitus and oral tumors in hungary: a long-term comparative epidemiological study. Anticancer Res. 2017;37(4):1853-1857.

45. Dixon JL, Copeland LA, Zeber JE, MacCarthy AA, Reznik SI, Smythe WR, Rascoe PA. Association between diabetes and esophageal cancer, independent of obesity, in the United States Veterans Affairs population. Dis Esophagus. 2016;29(7):747-751.

46. Sako A, Kitayama J, Kaisaki S, Nagawa H. Hyperlipidemia is a risk factor for lymphatic metastasis in superficial esophageal carcinoma. Cancer Lett. 2004;208(1):4349.

47. Tanaka T, Shimizu M, Kochi T, Shirakami Y, Mori T, Watanabe N, Naiki T, et al. Apc-Mutant Kyoto Apc Delta (KAD) rats are susceptible to 4-NQO-Induced Tongue Carcinogenesis. Cancers (Basel). 2014;6(3):1522-1539.

48. Feller L, Khammissa RAG, Lemmer J. Biomechanical cell regulatory networks as complex adaptive systems in relation to cancer. Cancer Cell Int. 2017;17:16.

49. Tanaka T. Colorectal carcinogenesis: Review of human and experimental animal studies. J Carcinog. 2009;8:5.

50. Hanahan D, Weinberg RA. Hallmarks of cancer: the next generation. Cell. 2011;144(5):646-674.

51. Hsue SS, Wang WC, Chen CH, Lin CC, Chen YK, Lin LM. Malignant transformation in 1458 patients with potentially malignant oral mucosal disorders: a follow-up study based in a Taiwanese hospital. J Oral Pathol Med. 2007;36(1):25-29.

52. Taylor PR, Abnet CC, Dawsey SM. Squamous dysplasia - the precursor lesion for esophageal squamous cell carcinoma. Cancer Epidemiol Biomarkers Prev. 2013;22(4):540-552.

53. Opitz OG, Harada H, Suliman Y, Rhoades B, Sharpless NE, Kent R, Kopelovich L, et al. A mouse model of human oral-esophageal cancer. J Clin Invest. 2002;110(6):761769.

54. Opitz OG, Quante M, von Werder A, Heeg S, Blum HE. A mouse model of oral-esophageal carcinogenesis. Onkologie. 2005;28(1):44-48.

55. Yang Z, Guan B, Men T, Fujimoto J, Xu X. Comparable molecular alterations in 4-nitroquinoline 1-oxide-induced oral and esophageal cancer in mice and in human esophageal cancer, associated with poor prognosis of patients. In Vivo. 2013;27(4):473-484. 